\title{
Ulrich Schmitzer \\ Sidonius Apollinaris - unfruchtbare Muse oder Erneuerung der Poesie im Zeichen des Mythos?
}

\begin{abstract}
Forte pater superum prospexit ab aethere terras: ecce viget quodcumque videt; mundum reparasse aspexisse fuit; solus fovet omnia nutus. Iamque ut conveniant superi, Tegeaticus Arcas nunc plantis, nunc fronte volat, vix contigit arva et toto descendit avo, mare, terra vel aer indigenas misere deos. Germane Tonantis, prime venis, viridi qui Dorida findere curru suetus in attonita spargis cito terga serenum; umentes Nymphas Phorcus comitatur ibique glaucus, Glauce, venis, vatum et certissime Proteu, certus eras. Longo veniunt post ordine divi:
\end{abstract}

Zufällig blickte der Göttervater vom Himmel auf die Erde herab. Siehe da, alles ist rege und bewegt sich, was auch immer er sieht. Die Welt angesehen zu haben, hieß, sie wiederhergestellt zu haben. Ein einziges Nicken belebt alles. Und damit die Götter nun zusammenkommen, fliegt der Arkadier aus Tegea bald mittels seiner Schuhe, bald mittels seines Flügelhutes auf der Stirn. Und kaum erreichte er die Fluren und stieg ganz von seinem Großvater Atlas herab, da schickten Meer, Erde und Luft ihre eigenen Götter. Du, Bruder des Donnerers, kommst als erster, der du mit grünem Wagen Doris, die Meeresflut, zu teilen pflegst und schnell über deren erstaunten Rücken heitere Ruhe verteilst. Phorcus, begleitet die feuchten Nymphen, und dort kommst du, Glaucus, und du, der untrüglichste aller Seher, Proteus, warst es sicher. Und in langer Reihe kommen danach die Götter ... ${ }^{1}$

In der Tat kommen dann die von Merkur, dem arkadischen Götterboten, herbeigerufenen Bacchus, Mars, Hercules, Venus, Ceres, Diana, Iuno, Minerva, Cybele, Saturn, Apollo, Pan, Faunus, die Satyrn, Castor und Pollux, Perseus, Vulcan, Tiphys und schließlich der vergöttlichte Romulus. Sie alle finden sich mit Jupiter zur einer Ratsversammlung zusammen, zu einer Götterversammlung, wie sie die antike Literatur seit der Ilias kennt und wie sie im lateinischen Bereich durch Ennius, Vergil und Ovid zum konstitutiven erzählerischen Bauelement des Epos wurde. ${ }^{2}$ Das transferiert das con-

1 Sidon. carm. 7,17-29 - Sidonius ist zitiert nach Sidoine Apollinaire, text établi et traduit par André Loyen, 3 Bände, Paris 1960-1970; wichtig auch wegen der Sachanmerkungen Sidonius, Poems and Letters, with an English Translation, Introduction, and Notes by W. B. Anderson, 2 Bände, London/ Cambridge, Mass. 1936/1965. Forschungsbericht von Silvia Condorelli, Prospettive Sidoniane. Venti anni di studi su Sidonio Apollinare (1982-2002), Bollettino di studi latini 33 (2003), 140-174.

2 Siehe Markus Janka, Wenn Götterväter zürnen ...: von Zeus und Aigisth zu Jupiter, Augustus und Lykaon, Hermes 127 (1999), 345-355. Eine (weitgehend unkommentierte) Zusammenstellungen der Bezüge auf frühere Dichter (aus der Wortebene) findet sich bei Robert E. Colton, Some Literary Influences on Sidonius Apollinaris, Amsterdam 2000. 
cilium deorum aus der epischen Narration in das durch einen Herrscher und dessen Lob qua Analogie zum Göttervater bestehende Kraftfeld. ${ }^{3}$ Und noch einen wesentlicheren Unterschied gibt es: Der Verfasser dieser Verse lebt anders als seine großen Vorgänger in einer Umwelt, in der das pagane Denken seine Selbstverständlichkeit verloren hatte, in der auch die staatlichen Würdenträger längst zu Christen geworden waren - was auch immer das im Einzelfall konkret bedeuten mochte. Der soeben vorgestellte Textausschnitt ${ }^{4}$ ist auch keineswegs das Produkt etwa heimlich ausgelebter paganer Nostalgie, sondern öffentlich und in hochpolitischem Kontext situiert, handelt es sich doch um den Panegyricus, den der junge Sidonius Apollinaris am 1. Januar 456 auf Avitus ${ }^{5}$ zum Antritt von dessen Kaiserkonsulat in Rom hielt. ${ }^{6}$ Sidonius war sogar in offizieller Mission unterwegs, hatten ihn doch die Städte seiner Heimat Gallien entsandt, um den Kontakt mit Avitus - gleichfalls Gallier und sogar der Schwiegervater des Sidonius - aufrecht zu erhalten und möglichst davon zu profitieren. Es liegt aufgrund dieser Konstellation die Vermutung nahe, dass Sidonius vernünftigerweise mit einer wohlwollenden Aufnahme seiner Verse, also auch mit der Referenz auf den paganen Mythos, rechnen konnte. ${ }^{7}$ Wie aber passen heidnische Götter, die in ihrem Rat über die richtige Besetzung des Herrscheramtes entscheiden und natürlich (wie ex post deutlich wird) die richtige Wahl treffen, zu einem christlichen Kaiser?

Bevor wir dem weiter nachgehen, sei zunächst ein kurzer Blick auf Sidonius Apollinaris und dessen Biographie geworfen. Sidonius ${ }^{8}$ wurde ca. 430 in Gallien geboren ${ }^{9}$ und gehörte einer bedeutenden aristokratischen Familie an, ${ }^{10}$ durch die Heirat

3 Antonella Bruzzone, Il „concilium deorum “ nella poesia panegiristica latina da Claudiano a Sidonio Apollinare, in: Anna Maria Taragna (Hrsg.), La poesia tardoantica e medievale. Atti del II convegno internazionale di studi, Perugia, 15-16 novembre 2001, Alessandria 2004, 129-141, bes. 135 f.

4 Vgl. auch Claudia Schindler, Per carmina laudes. Untersuchungen zur spätantiken Verspanegyrik von Claudian bis Coripp, Berlin/New York 2009 (Beiträge zur Altertumskunde 253), 182-198, 186, Anm. 55 zur schwierigen Textkonstitution in carm. 7,20 (Tegeaticus Arcas vs. Tegeaticus ales).

5 Kurzer Uberblick bei Klaus-Peter Johne, Avitus [1], DNP 2 (1997), 372.

6 Alexander Demandt, Geschichte der Spätantike. Das Römische Reich von Diocletian bis Justinian, München 1998, 142; zu Sidonius und Rom siehe Ralf Behrwald, Das Bild der Stadt Rom im 5. Jh. Das Beispiel des Sidonius Apollinaris, in: Therese Fuhrer (Hrsg.), Rom und Mailand in der Spätantike, Berlin 2011, 283-302.

7 Zur politischen Situation, in der Panegyricus vorgetragen wurde, siehe Hagith S. Sivan, Sidonius Apollinaris, Theodoric II, and Gothic-Roman Politics from Avitus to Anthemius, Hermes 117 (1989), 8594 sowie Andrew Gillett, Envoys and Political Communication in the Late Antique West, 411-533, Cambridge 2003, 84-112; außerdem immer noch André Loyen, Recherches historiques sur les Panégyriques de Sidoine Apollinaire, Paris 1942, 35-58.

8 Vgl. immer noch die Tabelle in Courtenay E. Stevens, Sidonius Apollinaris and his Age, Oxford 1933, XIIIf.; umfassend zum politischen Rahmen und der weltlichen und kirchlichen Laufbahn Jill Harries, Sidonius Apollinaris and the Fall of Rome AD 407-485, Oxford 1994, bes.75-81 (zu Sidonius und Avitus in Rom).

9 Vgl. Helga Botermann, Wie aus Galliern Römer wurden. Leben im Römischen Reich, Stuttgart 2005, 382-417. 
mit Papanilla, der Tochter des Avitus, wurde sein sozialer Status weiter aufgewertet. Er genoss eine sehr umfangreiche Erziehung, die ihn mit den klassischen lateinischen Autoren aufs engste vertraut machte. ${ }^{11}$ Er unterstützte zunächst - wie eingangs festgehalten - den weströmischen Kaiser Avitus, später dessen Nachfolger Maiorianus, die beide zeittypisch rasch ums Leben kamen. Danach zog sich Sidonius in den 60er Jahren des 5. Jahrhunderts ins Privatleben zurück, bis er 467 abermals der Bitte seiner gallischen Mitbürger folgte und nach Rom, zum jetzigen Kaiser Anthemius, reiste, um Schutz vor der Bedrohung Galliens durch die Westgoten zu erbitten. Dies war die Zeit, in der auch in Gallien die administrativen Strukturen geradezu erdbebenartig zusammenbrachen, und als Sidonius ca. 468 zurückkehrte, sah er sich gezwungen, das Bischofsamt von Clermont ${ }^{12}$ zu übernehmen, um damit nicht so sehr geistlich denn politisch zu wirken und den vordrängenden Westgoten entgegenzutreten. Das war keineswegs von dauerhaftem Erfolg gekrönt, vielmehr war v.a. die Stadt Clermont bedrohlichen Angriffen und langandauernden Belagerungen ausgesetzt. Sidonius starb mitten in diesen Wirren irgendwann in den 480er Jahren. ${ }^{13} \mathrm{Er}$ hinterließ ein nicht nur angesichts der Zeitumstände außerordentlich umfangreiches literarisches Werk, das 147 Briefe in neun Büchern ${ }^{14}$ umfasst sowie eine nach carmina maiora und carmina minora gegliederte Gedichtsammlung. Die carmina maiora enthalten die panegyrischen hexametrischen Poeme (wie den eingangs anzitierten Panegyricus auf Avitus) samt ihren Begleitgedichten. Die carmina minora stammen aus Sidonius' vorepiskopaler Lebensphase und sind deutlich als ein zusammengehöriges Gedichtbuch markiert und schließen mit einem Abschiedsgedicht an das Buch, einem Propempticon.

Sidonius gehört also zur aristokratischen Elite Galliens, ${ }^{15}$ wie es sich etwa eine Generation früher auch über Ausonius aus Bordeaux ${ }^{16}$ sagen lässt. Er hatte eine

10 Siehe generell Patrizia Mascoli, Gli Apollinari. Per la storia di una famiglia tardoantica, Bari 2010, bes. $23-33$.

11 Knappe Bemerkungen bei Botermann (s. Anm. 9), 403f.; vgl. auch generell Johannes Christes, Richard Klein, Christoph Lüth (Hrsgg.), Handbuch der Erziehung und Bildung in der Antike, Darmstadt 2006 (jeweils die Kapitel zur Spätantike); außerdem Ágnes T. Horváth, The Education of Sidonius Apollinaris in the Light of his Citations, Acta classica Universitatis Scientiarum Debreceniensis 36 (2000), 151-162; Pierre Riché, La survivance des écoles publiques en Gaule au Ve siècle, Le Moyen Age 63 (1957), 421-436 (auch zu Sidonius' späterer bildungspolitischer Tätigkeit); zuletzt generell Edwad Watts, Education: Speaking, Thinking, and Socializing, in: Scott Fitzgerald Johnson (Hrsg.), The Oxford Handbook of Late Antiquity, Oxford 2012, 467-486.

12 Vgl. auch Joop van Waarden, Sidonio Apollinare, poeta e vescovo, VetChr 48 (2011), 99-113.

13 Das Epitaph (aufbewahrt im Musée Bargonin, Clermont-Ferrand) ist bequem mit Abbildung und Transkription zugänglich unter www.sidoniusapollinaris.nl (Sektion: Texts, Links \& More).

14 Zur Bedeutung der Briefe des Sidonius als Mittel des geistigen Widerstandes gegen die Goten und die Rolle der traditionellen Bildung dabei siehe Oliver Overwien, Kampf um Gallien. Die Briefe des Sidonius Apollinaris zwischen Literatur und Politik, Hermes 137 (2009), 93-117.

15 Vgl. Scott McGill, Latin Poetry, in: Scott Fitzgerald Johnson (Hrsg.), The Oxford Handbook of Late Antiquity, Oxford 2012, 340f. zum literarischen Leben in Gallien. 
sorgfältige Ausbildung genossen, die keineswegs die klassischen Bildungsautoren allen voran den (kommentierten ${ }^{17}$ ) Vergil - zugunsten der christlichen Glaubenstrakte in den Regalen verstauben ließ. Für Sidonius ist vielmehr die in den kanonischen Werken der Literatur repräsentierte Geschichte des Imperium Romanum und die zugrunde liegenden Werte ein wesentlicher Faktor seines Denkens, so dass durch diese Romanitas auch die Götter aus der Zeit der römischen Größe zumindest als Teil der Tradition darin ihren Platz fanden. ${ }^{18}$

Doch die alte, biographistisch angehauchte Frage nach der "Authentizität" von Literatur, also von der Identität der Persönlichkeit des Verfassers mit den tragenden Gedanken seiner Werke, führt(e) nicht selten zu einer negativen ästhetischen Bewertung von Sidonius' Dichtungen. ${ }^{19}$ C. E. Stevens beispielsweise, der vor achtzig Jahren eine prinzipiell immer noch hilfreiche Sidonius-Monographie verfasste, urteilt unmissverständlich über die zu Beginn zitierte Passage:

This is very uninspired writing. It is worse than mere padding, it is very bad padding ... Even the account of Rome's past, which is not pointless, is so over-elaborated that ... it fails in its effect and the point of contrast is lost. Yet, with all its fault, this poem, the first of his that is preserved, is in some ways the best that Sidonius ever wrote. ${ }^{20}$

Das ist eine sehr deprimierende Diagnose, die im Grunde genommen diesen gesamten Beitrag in seiner Berechtigung in Frage stellt. Demnach hätte es der politisch und kirchenpolitisch erfolgreiche, hoch gebildete Sidonius nicht vermocht, aus diesen Voraussetzungen ein auch nur halbwegs überzeugendes Ergebnis zu generieren. Das impliziert zugleich ein generelles Verdikt über die literarischen Potentiale dieser Zeit. Die Autoren können nicht mehr aus Eigenem Größe erreichen, sondern nur noch - wie der Mond das Sonnenlicht - literarisch wie politisch Großes reflektieren:

It is a notable fact about Sidonius' poetry, and indeed a commentary on his mind, that he could not create heroic figures. He could only write up to a noble subject, but he could not himself ennoble it. ${ }^{21}$

16 Jüngste Zusammenfassung bei Joachim Gruber, D. Magnus Ausonius, Mosella. Kritische Ausgabe, Übersetzung, Kommentar, Berlin/Boston 2013 (Texte und Kommentare 42), 9-13; vgl. auch dessen Zusammenstellungen unter http://joachimgruber.userweb.mwn.de/ausonius.html.

17 Zuletzt Alan Cameron, The Last Pagans of Rome, Oxford 2011, 567-626.

18 Vgl. Lynette Watson, Representing the Past, Redefining the Future: Sidonius Apollinaris' Panegyrics of Avitus and Anthemius, in: Mary Whitby (Hrsg.), The Propaganda of Power. The Role of Panegyric in Late Antiquity, Leiden/Boston/Köln 1998,177-198, bes. 191-195; außerdem Frank-Michael Kaufmann, Studien zu Sidonius Apollinaris, Frankfurt am Main et al. 1995, 81-105.

19 Der Illustration für diese traditionelle Position halber sei das Urteil in Teuffels „philologischem Reichskursbuch“ zitiert: „Der begabteste Vertreter der Strebsamkeit und Formgewandtheit, aber auch der Gedankenarmut und Phrasenhaftigkeit der gallisch römischen Literatur der Zeit ist C. Sollius Apollinaris Sidonius ...“ (Wilhelm Teuffel, Geschichte der römischen Literatur, Leipzig 1870, 967).

20 Stevens (s. Anm. 8), $32 \mathrm{f}$.

21 Stevens (s. Anm. 8), 33. 
Noch gut siebzig Jahre später urteilt Gernot Krapinger im Neuen Pauly nicht wesentlich freundlicher:

Weder in den Briefen noch in den Gedichten entfernt sich S. in Wortschatz, Flexionssystem und Syntax weit von seinen Vorbildern Statius, Ovidius, Vergilius, Horatius, Claudianus ..., Silius ... Italicus und Ausonius bzw. für die Prosa Plinius, Symmachus ... und Cicero ... Die übermäßige Verwendung von Alliterationen, Homoioteleuta, Paronomasien und Klangspielereien ist dem Gesamtwerk ebenso eigen wie der Hang zu längeren Perioden, Hyperbolen und Synekdochen, Metonymien und Periphrasen (... eine ,späte Nachwirkung des Asianismus'). S. fußt stark auf paganem Bildungsgut, seine Zugehörigkeit zur christl. Kirche kommt selten zum Tragen, an einer denkerischen Auseinandersetzung zw. christl. und nichtchristl. Positionen ist er nicht interessiert. Auch philos. oder theologische Dispute sind seine Sache nicht, dazu ist seine Freude am Konkreten, Anschaulichen und Polit.-Praktischen zu ausgeprägt. ${ }^{22}$

Sidonius, so scheint es, hat noch nicht so recht Anteil an der generellen Neubewertung der spätantiken Literatur gewonnen, in deren Gefolge die Eigenständigkeit gegenüber aus klassizistischen Paradigmen abgeleiteten Deszendenzmodellen betont wurde und ein Claudian, aber auch ein Ausonius wieder unter die Autoren gezählt wird, deren sich die Latinistik nicht zu schämen braucht. Demnach ist die Qualitätsproblematik auch unter der hier verfolgten Fragestellung alles andere als marginal, entscheidet sich doch daran, ob die Präsenz des Mythos bei Sidonius als dysfunktionale Einsprengsel oder als Teil eines umfassenden poetischen Konzepts auf der Höhe der Zeit zu bewerten ist. ${ }^{23} \mathrm{Ob}$ sich draus eventuell sogar eine generelle Rehabilitation des Sidonius ableiten lässt (oder nicht), wird sich noch zeigen.

Die Untersuchung dieser Frage vollzieht sich auf zwei (unterschiedlich ausführlich dargestellten) Ebenen: Im Bereich der "großen“, Politisches betreffenden Literatur war durch den „Staatsdichter“ Claudian den Weg bereitet, als er schon am Ende des 4. Jahrhunderts den traditionellen Götterapparat - und mit ihm die Götterversammlung - literarisch rettete und selbst für dezidiert christliche Herrscher ganz und gar akzeptabel machte. Demnach ist es keine literarische Revolution, dass Sidonius sich des paganen mythologischen Apparats bedient, sogar wenn er die Götterinvokation gegenüber Claudian noch deutlich ausweitet. ${ }^{24}$ Dieser Befund gilt auch dann, wenn Claudia Schindler recht hat und Claudian im Vergleich zu seinen Vorgängern aus augusteischer Zeit und früher Kaiserzeit die Rolle der Götter gegenüber den menschlichen Protagonisten erheblich beschnitten hat, um auf diese Weise die Herrscher stärker hervorzuheben, als es in der paganen Tradition der Fall gewesen war; ${ }^{25}$ denn die schiere

22 Gernot Krapinger, Sidonius Apollinaris, DNP 11 (2001), 522 f., hier: 523.

23 Siehe auch den Beitrag in diesem Band von Winrich Löhr, Christliche Bischöfe und klassische Mythologie in der Spätantike (mit Blick auf Augustinus und v.a. den griechischen Sprachraum).

24 Schindler (s. Anm. 4), 185-187.

25 Claudia Schindler, Claudians „pagane“ Götter. Tradition und Innovation in der spätantiken Panegyrik, Gym 115 (2008), 331-345; außerdem generell Schindler (s. Anm. 4) zur antiken Verspanegyrik (ohne spezielles Interesse an der pagan-christlichen Thematik); zu Sidonius' panegyrischen Dichtungen für Maiorianus (und deren mythologischen Elementen) siehe Severin Koster, Princeps und 
Möglichkeit der Präsenz des paganen Apparats und dessen literarische Etablierung ist doch ein starkes Zeichen für die folgenden Dichter. Offenbar ist es nach dem Ende der tatsächlichen ideologischen Auseinandersetzungen, die noch weite Strecken des 4. Jahrhunderts prägten, nun möglich, panegyrisches Schreiben in der traditionellen Form fortzuführen, ohne dass die Geehrten daran Anstoß genommen hätten (das ist ein wichtiges Indiz dafür, dass zumindest die Zeitgenossen den Versuch als gelungen angesehen haben, denn der Unwille eines verunglückt gepriesenen Herrschers wäre der weiteren Karriere gewiss nicht förderlich gewesen).

Liest man die solcherart entstandene Literatur nur mit der Intention, daraus Glaubensaussagen des Verfassers - und zwar hundertprozentig authentische - zu gewinnen, dann kann man wohl zu einem Ergebnis kommen, wie es Alan Cameron provozierend formuliert:

If all we had from the pen of Sidonius Apollinaris was his imperial panegyrics, and we knew nothing about his life beyond these poems, it might well have been argued that he was pagan. ${ }^{26}$

Ein solches Resultat zeigt natürlich die Absurdität der zugrundeliegende Fragestellung, eine Frage, die man u.a. an die als „Namenschristen“ apostrophierten Claudian und Ausonius gerichtet hatte. ${ }^{27}$ Und so ist es nur konsequent, wenn die neuere Forschung über die spätantike Literatur diese uralte Erkundigung nach dem Verhältnis von persönlicher Religiosität ${ }^{28}$ und literarischem Anspruch ad acta legt. ${ }^{29}$

Vielleicht ist das Fortbestehen der traditionellen panegyrischen (oder allgemeiner: literarischen) Form vergleichbar mit dem Fortbestand der römischen Repräsentationsbauten. Der Palatin wurde nicht als Herrschersitz aufgegeben (wenn denn der römische Kaiser tatsächlich einmal in Rom war), mochte er sich auch auf die paganen Helden Euander, Aeneas und Romulus zurückführen. Auch die Stadt Rom insgesamt wurde nicht von den sichtbaren Resten des Heidentums gereinigt, die Tempel blieben

poeta in Lyon (Sidon. carm. 3, 4, 13), in: Udo Kindermann, Wolfgang Maaz, Fritz Wagner (Hrsgg.), Festschrift für Paul Klopsch, Göppingen 1988, 293-307.

26 Cameron (s. Anm. 17), 206; eher vermittelnd ist neuerdings wieder Jaclyn Maxwell, Paganism and Christianization, in: Scott Fitzgerald Johnson (Hrsg.), The Oxford Handbook of Late Antiquity, Oxford 2012, 849-875.

27 Das ist im Grunde genommen das große Thema von Cameron (s. Anm. 17) passim. Zu Ausonius siehe auch Joachim Gruber, Plekos 15 (2013), 91-95 (Rez. von Paul Dräger, Ausonius: Sämtliche Werke, Bd.1, Trier 2012), hier: 94 mit Anm. 7 zur Frage nach dem Verhältnis des Ausonius zum Christentum (mit weiterer Literatur).

28 Für den griechischen Bereich stellt sich ja ein vergleichbares Problem für Nonnos: Zur Erklärung des Nebeneinanders von christlichen und paganen Werken ist man immer wieder auf biographistische Modelle ausgewichen; vgl. den Beitrag von Domenico Accorinti in diesem Band.

29 In grundsätzlich vergleichbarer Weise stellt auch Jörg Rüpke (Geteilte und umstrittene Geschichten: Der Chronograph von 354 und die Katakombe an der via Latina - in diesem Band) die „binäre Opposition“ Heidentum vs. Christentum zugunsten einer „neue[n] Perspektive auf den Stellenwert der Religion innerhalb der spätantiken Gesellschaft sowie die komplexe Beschaffenheit von Religion“ in Frage. 
im Zentrum stehen - selbst der der Venus und Roma -, und niemand störte sich daran, allenfalls Prudentius. Die Taliban-Lösung, die gewaltsame Auslöschung aller Spuren einer unliebsamen Vergangenheit (wie im Artilleriebeschuss der Buddha-Statuen von Bamiyan in Afghanistan 2001), war weder im urbanen Raum des Westens (auf dem Land konnte es anders aussehen) noch in der Literatur eine tatsächliche Option. Die pagane Gedankenwelt wird gleichsam eingekapselt und damit ihrer Brisanz beraubt, da sie eine öffentliche Funktion zu erfüllen hat, für die das Christentum keinen wirklichen Ersatz bieten konnte. ${ }^{30}$ Umgekehrt musste sich der gallische Landsmann des Sidonius, Ausonius aus Bordeaux, sich nicht ganz ein Jahrhundert zuvor durchaus um Freiraum mühen, wie aus der Debatte mit seinem Verwandten Paulinus von Nola, ${ }^{31}$ aber auch implizit aus dem Cento nuptialis ablesen lässt, indem er sich gegen naivchristliche Usurpation Vergils im Cento der Proba verwahrte.

Doch lässt sich der anhand der panegyrischen Dichtung und deren spezifischen Bedingungen ${ }^{32}$ erhobene Befund einer selbstverständlichen Instrumentalisierung des Mythos einfach auf andere poetische Formen, auf die Persönliches behandelnde Kleindichtung z. B., übertragen und damit generalisieren? Denn wesentlich brisanter als in der Großdichtung scheint die Präsenz des Paganen in der Kleindichtung, die sich viel stärker als eine persönliche Dichtung geriert, bekenntnishaft erscheint und vermeintlich einen Blick auf den Autor selbst freigibt. ${ }^{33} \mathrm{Um}$ darüber genaueren Aufschluss $\mathrm{zu}$ erhalten, sei jetzt der Blick auf das bereits genannte Gedichtbuch der carmina minora $^{34}$ gerichtet und hier wiederum exemplarisch auf das carmen $9 .{ }^{35}$

Dieses Gedicht trägt die Widmung des gesamten Buches an Magnus Felix, ${ }^{36}$ der 469 als Praefectus Praetorio Galliarum belegt ist, also an einen Angehörigen der gallorömischen Elite. Mit einer solchen Dedikation stellt sich Sidonius in eine lange Reihe von Buchanfängen in der lateinischen Dichtung. Der erste Beleg findet sich bei Catull

30 Zur Unverzichtbarkeit des mythischen Stoffes s. Schindler in diesem Band.

31 Siehe David Amherdt, Ausone et Paulin de Nole: correspondance. Introduction, texte latin, traduction et notes, Bern et al. 2004, 23-25.

32 Die (tages-)politische Bedeutung der Panegyrici verbietet es, den dort verwendeten Götterapparat nur als fiktionales Bildungsgut zu sehen (wie in anderen Bereichen, dazu den Beitrag von Löhr in diesem Band), vielmehr muss es eine Harmonie von Form und Inhalt gegeben haben.

33 Siehe prinzipiell Martin Hose, Das lyrische Ich und die Biographie des Lyrikers. Überlegungen zu einem alten Problem und seinem Nutzen, in: Markus Schauer, Gabriele Thome (Hrsgg.), Altera Ratio. Klassische Philologie zwischen Subjektivität und Wissenschaft. Festschrift für Werner Suerbaum zum 70. Geburtstag, Stuttgart 2003, 42-61.

34 Siehe den Überblick bei Condorelli (s. Anm.1), 163-164; Willy Schetter, Zur Publikation der Carmina minora des Apollinaris Sidonius, Hermes 120 (1992), 343-363 = in: ders., Kaiserzeit und Spätantike. Kleine Schriften 1957-1992, Wiesbaden 1994, 236- 256 (hiernach zitiert), hier: 256: Das ursprüngliche Gedichtbuch enthielt demnach alle Gedichte bis auf carm. 22 und 23 und wurde um 462 publiziert. 35 Zum Aufbau siehe Stefania Santelia, Le dichiarazioni del poeta. Il carme IX di Sidonio Apollinare, Invigilata lucernis 20 (1998), 229-254; angekündigt ist ein Kommentar der Verfasserin zu den gesamten carmina minora; siehe www.sidoniusapollinaris.nl (Sektion: „Bibliography: in preparation/in press“). 36 PLRE 2, 463 f.; Dirk Henning, Periclitans res publica. Kaisertum und Eliten in der Krise des weströmischen Reiches 454/5-493 n.Chr., Wiesbaden 1999, 91; Kaufmann (s. Anm. 18), 306-308. 
im carmen 1, gerichtet an Cornelius (Nepos): cui dono lepidum novum libellum ...? Corneli tibi: Eine Gedichtsammlung wird in einem solchen Verfahren nicht zuletzt durch ihren Adressaten nobilitiert. Während allerdings Catull seine Kleindichtung privaten Inhalts auch in einer auf wenige Verse konzentrierten Form vorstellt, ist das bei Sidonius ganz anders, wenn er sich von der politisch-panegyrischen Großdichtung abwendet. Denn wohl schreibt er (carm. 9,9-13): ${ }^{37}$

quid nugas temerarias amici,

sparsit quas tenerae iocus iuventae,

in formam redigi iubes libelli, ingentem simul et repente fascem conflari invidiae et perire chartam?

Was befiehlst du, die verstandeslosen Kleinigkeiten des Freundes, die der Scherz der zarten Jugend ausstreute, in die Gestalt eines kleinen Buches zu bringen, und zugleich plötzlich ein riesiges Bündel an Neid zu schnüren und das Papier zu verderben.

Sidonius greift mit nugae und libellus sowie charta Catullische Themenwörter auf, die im ersten Gedicht des Neoterikers seine Position und die seines patronus markierten. ${ }^{38}$ Obendrein ist das gesamte Gedicht im Hendecasyllabus gehalten, einem durch Catull prominent gemachten Metrum. ${ }^{39}$ In diese Übernahme der neoterischen Gedankenwelt gehört auch das Auftreten des Neids - den ФӨóvoৎ hatte Kallimachos mit einem Fußtritt hinausbeförder ${ }^{40}$ - sowie die Charakterisierung solcher poetischer Bemühungen als Jugenddichtungen, unabhängig vom tatsächlichen Lebensalter bei der Entstehung der Gedichte. ${ }^{41}$ Denn spätestens seit den biographischen Schemata zu Vergil beginnt eine Dichterlaufbahn in der Jugend mit geringen Gedichten nach Art des Catalepton, um sich dann mit fortschreitendem Alter über Bukolik und Georgik zu den epischen Höhen der Aeneis zu erheben. ${ }^{42}$

Was Sidonius allerdings grundlegend von seinem neoterischen Vorgänger unterscheidet, ist das Fehlen von brevitas (trotz des Diminutivs libellus). Vielmehr war auch den zitierten Versen bereits eine ausführliche Würdigung von Felix' Rang, insbesondere seines Familienstandes vorausgegangen. Offenbar ist es eben nicht mehr

37 Vgl. Santelia (s. Anm. 35), 239 zu weiteren Anspielungen auf Catull und Martial.

38 Auch iubes gehört zur Terminologie des literarischen patronus-cliens-Verhältnisses wie bei Prop. 1,3, vgl. auch die haud mollia iussa des Maecenas in Verg. georg. 3,40.

39 Siehe auch Jesús Hernández Lobato, „Sterilis Camena“. El Carmen 9 de Sidonio Apolinar o la muerte de la poesia, ACME 63 (2010), 97-133, hier: 98.

40 Severin Koster, Kallimachos als Apollonpriester, in: ders., Tessera. Sechs Beiträge zur Poesie und poetischen Theorie der Antike, Erlangen 1983 (Erlanger Forschungen A,30), 9-23.

41 Vgl. Ulrich Schmitzer, Jakob Baldes Batrachomyomachie, Paideia 66 (2011), 491-518, hier: 495 zu ähnlichen Verfahren bei Jakob Balde, der die „leichte" Batrachomyomachie zu einem Jugendgedicht erklärte, unabhängig vom tatsächlichen Entstehungszeitpunkt.

42 Vgl. zuletzt Ulrich Schmitzer, Strategien der Selbstkanonisierung bei Ovid, in: ders. (Hrsg.), Enzyklopädie der Philologie. Themen und Methoden der Klassischen Philologie heute, Göttingen 2013 (Vertumnus 11), 51-81, bes. 51 f. 
opportun, eine solche lobende Erwähnung in catullischer Knappheit vorzunehmen. Die geänderten Usancen hätten das als ungebührlich schroff erscheinen lassen, auch im Rahmen von personaler Dichtung war jetzt Ausführlichkeit oder gar Exuberanz nötig. Der Rekurs auf die frühere römische Dichtung, personifiziert in Catull, ist also bei aller stilistisch-poetologischen Aufgeladenheit des Vokabulars in erster Linie durch Thematik und damit verbundene Stilhöhe gewonnene Aussage über Kleindichtung, nicht durch den Umfang. Dennoch hat Sidonius bei allen Unterschieden damit einen die traditionelle lateinische Dichtung aufgreifenden Rahmen gesetzt, der nicht nur die Form, sondern auch die damit verbundenen Inhalte in den Focus rückt. Die Fortsetzung bewegt cum grano salis sich in den von der kallimacheisch inspirierten Dichtung vorgezeichneten Bahnen, indem Sidonius mit der Wegmetapher ${ }^{43}$ die Neuartigkeit seines Tuns unterstreicht.

Der Hauptteil des Gedichts, der gut 300 Verse umfasst, bringt jedoch schon zu Beginn eine Überraschung. Denn Sidonius nennt keineswegs, was er auf dieser poetologischen Basis nun eigentlich dichten möchte, sondern was er nicht zum Thema macht. Diese Priamelreihe ist eine ins Gigantische gesteigerte kallimacheische recusatio, ${ }^{44}$ die mit einer klaren Absage an traditionelle Stoffe einsetzt (carm. 9,16-18):

\section{Non nos currimus aggerem vetustum nec quicquam invenies ubi priorum antiquas terat orbitas Thalia.}

Wie laufen nicht einen alten Weg $^{45}$ entlang und du wirst nichts finden, wo Thalia die alten Wagenspuren der Früheren durchfurcht.

Thalia ist generell die Muse der leichten und kleinen Dichtung, spätestens seitdem Vergil seine 6. Ekloge ebenfalls mit dem Anspruch auf Neuartigkeit eingeleitet hatte: Prima Syracusio dignata est ludere versu ... nostra Thalia. Sie bezeichnet abermals Stilhöhe und generisches Milieu, nicht mit exakter Zuweisung das үદ́voৎ der Komödie, und führt damit wiederum ins kallimacheische Gedankengut.

Sidonius beginnt die Reihe des als Stoff Abgelehnten mit fremden Ländern und Völkern (19-37), kommt sodann in gleitendem Übergang zu den großen militärischen Leistungen von Marathon und den Thermopylen bis zu Alexander bei Gaugamela - er bietet also dezidiert keine Zeitgeschichte, sondern kanonisierte, als exemplum taugliche und noch dazu klassische griechische Historie. Sie wäre das genuine Thema von Historiographie oder in unserem Kontext historischer Epik, in jedem Fall von hoch auf der Skala literarischer Dignität angesiedelten Gattungen. Von da geht Sidonius

43 Walter Wimmel, Kallimachos in Rom. Die Nachfolge seines apologetischen Dichtens in der Augusteerzeit, Wiesbaden 1960 (Hermes Einzelschriften 16), 103-111.

44 Lobato (s. Anm. 39), 109 mit konzentriertem Überblick über die negativ gewürdigten Dichter.

45 Für agger in der Bedeutung von via strata, „Straße, Weg“, siehe ThLL 1, s.v. agger, 1309,17-56 (seit Vergil und vor allem in der Spätantike). 
noch einen Schritt weiter zurück, in die Grauzone zwischen Geschichte und Mythos (carm. 9,65-75):

\begin{abstract}
Non vectos Minyas loquente silva dicam Phasiaco stetisse portu, forma percita cum ducis Pelasgi molliret rabidos virago tauros, nec tum territa, cum suus colonus post anguis domiti satos molares armatas tremebundus inter herbas florere in segetem stuperet hostem et pugnantibus hinc et hinc aristis supra belliferas madere glaebas culmosos viridi cruore fratres.
\end{abstract}

Ich will nicht davon künden, dass die Minyer, die mit dem sprechenden Baum des Waldes fuhren, im Hafen des Phasis Halt machten, während die Heldenjungfrau, bestrickt von der Schönheit des pelasgischen Anführers, die wilden Stiere besänftigte und auch dann nicht erschrocken war, als der von ihr zum Bauern Gemachte die Zähne der zahmen Schlange säte und zitternd mitten unter den bewaffneten Trieben staunte, dass der Feind zur Saat erblühte und dass, während die Ähren hierhin und dorthin kämpften, über den kriegsbringenden Schollen die halmgestaltigen Brüder vom grünen Blut trieften.

In preziösen Wendungen umreißt Sidonius die Grundzüge der Argonautensage, wie sie Apollonios Rhodios, Varro Atacinus und Valerius Flaccus in epischer Breite entwickelt hatten. Das ist gewissermaßen die Mutter aller Epen, da schon die homerische Odyssee die Fahrt der Argo und die damit verbundene kulturstiftende Leistung der Nautik als altbekanntes Narrativ voraussetzt (Hom. Od. 12,69-72): oïn $\delta \eta \dot{~ \kappa \varepsilon i v \eta ~}$

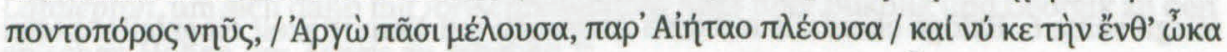

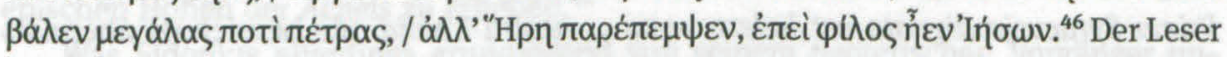
weiß allerdings noch nicht genau, wohin das nun führen wird, denn die Argonauten können sowohl für menschliche Großtaten stehen - und damit an die zuvor genannten militärischen Leistungen anknüpfen - oder mit chronologischer Inversion aus der Welt der Historie in den Mythos überleiten. Es wird sich zeigen, dass Letzteres der Fall ist.

Indem Sidonius die Argonautenerzählung prominent unter die abgelehnten Themen einreiht, schließt er sich zugleich an das Vergils Proömium zum 3. GeorgicaBuch an, der ebenfalls die Argonautensage, repräsentiert durch den Hylas-Mythos, zur Definition seines poetischen Programms ex negativo genutzt hatte (Verg. georg. 3,3-9): ${ }^{47}$

46 „Einzig ein meerbefahrendes Schiff fuhr dort vorbei: Argo, die alle in den Erzählungen beschäftigt, als sie von Aietes wegfuhr. Und auch sie hätte die Woge dort schnell an die großen Felsen geworfen, doch Hera geleitete sie vorbei, weil ihr Jason lieb war (Übers. von Wolfgang Schadewaldt).“

47 Siehe zum komplexen kallimacheischen Hintergrund und zur recusatio-Thematik zusammenfassend Virgil, Georgics, Vol. 2: Books III-IV, ed. by Richard F. Thomas, Cambridge 1988, z. St. 
cetera, quae vacuas tenuissent carmine mentes, omnia iam vulgata: quis aut Eurysthea durum aut inlaudati nescit Busiridis aras?

cui non dictus Hylas puer et Latonia Delos

Hippodameque umeroque Pelops insignis eburno,

acer equis? temptanda via est, qua me quoque possim

tollere humo victorque virum volitare per ora.

Alles Übrige, was im Gedicht die aufnahmebereiten Sinne fesseln, ist längst allgemein bekannt: Wer kennt nicht den harten Eurystheus oder die Altäre des ruhmlosen Busiris? Wem hat man nicht schon vom Knaben Hylas erzählt und vom Delos der Latona, von Hippodame und Pelops, berühmt wegen seiner Elfenbeinschulter, tollkühn zu Pferde. Ich muss einen Weg versuchen, auf dem auch ich mich von der Erde erheben kann und siegreich meinen Flug durch die Münder der Männer nehme.

Durch die Referenz auf Vergil wir für den kundigen Leser zugleich die Opposition "obsoleter Stoff vs. Innovation“ (also die Ablehnung bereits ad nauseam traktierter Stoffe) aufgerufen, die Sidonius überlagert durch die inhaltliche Frage nach abzulehnenden Mythen, die er in einer langen Reihe anschließt - nota bene: nach Mythen, nicht dem Mythos an sich. Von einer solchen prinzipiellen Verweigerung ist das gesamte Gedicht hindurch (und auch sonst) nicht die Rede. Allerdings hat Sidonius durch den Beziehungsrahmen bereits eine bestimmte Lesererwartung geweckt. Doch es dauert noch eine ganze Weile, bis entschieden ist, ob sie auch eingelöst (oder enttäuscht) werden wird.

Denn zunächst schließt sich mit ähnlichem Umfang wie für die Argonauten der Hinweis auf die Gigantomachie an (carm. 9,76-93) - ebenfalls ein traditionelles großepisches Thema ${ }^{48}$-, bevor mit erneut gesuchter Artistik die Taten des Hercules folgen, die ebenfalls bei Vergil kurz erwähnt sind (Vergils Busiris ist wohl Sidonius' hospes, Eurystheus ist der Auslöser für die Taten des Hercules; carm. 9,94-100):

Non hic Herculis excolam labores, cui sus, cerva, leo, Gigas, Amazon, hospes, taurus, Eryx, aves, Lycus, fur, Nessus, Libs, iuga, poma, virgo, serpens, Oete, Thraces equi, boves Hiberae, luctator fluvius, canis triformis portatusque polus polum dederunt.

Ich will hier nicht die Arbeiten des Hercules ausbreiten, dem Schwein (Eber), Hirschkuh, Löwe, Gigant, Amazone, Gastfreund, Stier, Eryx, Vögel, Lycus, der Dieb, Nessus, der Libyer, das Joch, der Apfel, die Jungfrau, die Schlage, Oete, die Thrakischen Pferde, die spanischen Rinder, der kämpfende Fluss, der dreigestaltige Hund und der getragene Himmel den Himmel gaben.

48 Philip Hardie, Virgil's Aeneid. Cosmos and Imperium, Oxford 1986 ist immer noch die beste Auseinandersetzung mit diesem Thema. 
Ob polus hier als Ausdruck für die Apotheose verwendet wurde, um das christlich konnotierte caelum zu vermeiden, ist immerhin eine Überlegung wert. Es wäre ein Indiz für eine literarische Konfliktvermeidungsstrategie. Wichtiger ist aber für Sidonius sicher die Assoziation mit dem höchsten Punkt des Himmelsgewölbes und das Polyptoton polus/polum, wofür er einen ganzen Vers aufwendet: Die aus den Taten resultierende Apotheose erhält mehr Raum als die sie letztlich herbeiführenden Taten je für sich. Sidonius kann nicht weniger als dreiundzwanzig um Hercules zentrierte Sagen in sechs Versen (eventuell ein numerisches Spiel mit den kanonischen zwölf Taten) unterbringen. ${ }^{49}$

Ein solche umfassende und zugleich aufs äußerste komprimierte Zusammenstellung der kanonischen und unkanonischen Taten ${ }^{50}$ des Hercules ist kein punktueller Einfall des Sidonius. In einem anderen Metrum, im Hexameter, und eine anderen Kontext, einem Hochzeitsgedicht auf ein ohne jeden Zweifel christliches Brautpaar aus der gallischen Aristokratie, ${ }^{51}$ versucht er sich im Rahmen der carmina minora noch einmal daran, indem er Hercules in die Ekphrasis von Festgewändern einreiht (carm. 15,135-145): ${ }^{52}$

\section{Amphitryoniadi surgebat tertia vestis: parvulus hic gemino cinctus serpente novercae inscius arridet monstris ludumque putando insidias dum nescit amat, vultuque dolentis exstingui deflet quos ipse interficit angues. \\ Praeterea sparsis sunt haec subiecta figuris, sus, leo, cerva, gigas, taurus, iuga, Cerberus, hydra, hospes, Nessus, Eryx, volucres, Thrax, Cacus, Amazon, Cres, fluvius, Libs, poma, Lycus, virgo, polus, Oete. Hoc opus, et si quid superest, quod numina vestit, virgineae posuere manus.}

Dem Amphitryonsprössling galt das dritte Gewand: Noch ganz klein, umwunden von den beiden Schlangen der Stiefmutter, lacht dieser unwissend die Ungeheuer an und, da er es für ein Spiel hält, liebt er die Nachstellungen, solange er sie nicht kennt, und mit der Miene eines Trauernden beweint er, dass die Schlangen, die er selbst getötet hat, nun ausgelöscht sind. Außerdem ist unter die verstreuten Gestalten dies eingefügt: Das Schwein, der Löwe, die Hirschkuh, der Gigant, der

49 Siehe auch Michael Roberts, The Jeweled Style. Poetry and Poetics in Late Antquity, Ithaca/London 1989, 59-61 über die Beliebtheit solcher kondensierter Aufzählung in der spätantiken Dichtung.

50 Frank Brommer, Herakles. Die zwölf kanonischen Taten des Helden in antiker Kunst und Literatur, Darmstadt ${ }^{5}$ 1986; ders., Herakles II. Die unkanonischen Taten des Helden, Darmstadt 1984; zu Herakles in christlichen Kontexten siehe Henrike Maria Zilling, Jesus als Held. Odysseus und Herakles als Vorbilder christlicher Heldentypologie, Paderborn 2011, bes. 139-224.

51 Siehe den Kommentar von Giovanni Ravenna (Hrsg.), Le nozze di Polemio e Araneola (Sidonio Apollinare, Carmina XIV-XV). Introduzione, testo, tradizione e commento, Bologna 1990, z. St. (auch zu den Quellen); Patrizia Mascoli, Personaggi femminili in Sidonio Apollinare, Invigilata lucernis 22 (2000), 89-107, hier: $94 \mathrm{f}$.

52 Zur Tradition der Verwendung des Mythos in lateinischen Epithalamien siehe Michael Roberts, The Use of Myth in Latin Epithalamia, TAPA 119 (1989), 321-348, zu Sidonius 338-344. 
Stier, die Joche, Cerberus, die Hydra, der Gastfreund, Nessus, Eryx, die Vögel, der Thraker, Cacus, die Amazone, der Kreter, der Fluss, der Libyer, die Jungfrau, das Himmelsgewölbe, Oeta. Dieses Werk, und, wenn es denn noch etwas gibt, was die Götter kleidet, haben die Hände der Jungfrauen es geschaffen.

Sidonius tritt mit diesem doppelten Versuch offenbar in einen poetischen Wettstreit ein, der sich in der Spätantike (oder genauer: in der Literatur des spätantiken Gallien) augenscheinlich einer gewissen Beliebtheit erfreut. Denn Sidonius' gallischer Landsmann Ausonius hatte diesem Thema ein ganzes Gedicht gewidmet, das in jeweils einem Vers eine Leistung des Heros aufführt (ecl. 17 Green): ${ }^{53}$

\section{(MONOSTICHA) DE AERVMNIS HERCVLIS}

Prima Cleonaei tolerata aenumna leonis.

Proxima Lernaeam ferro et face contudit hydram.

Mox Erymantheum vis tertia perculit aprum.

Aeripedis quarto tulit aurea cornua cervi.

Stymphalidas pepulit volucres discrimine quinto.

Thraeiciam sexto spoliavit Amazona balteo.

Septima in Augei stabulis inpensa laboris.

Octava expulso numeratur adoria tauro.

In Diomedeis victoria nona quadrigis

Geryone extincto decimam dat Hiberia palmam.

Undecimo mala Hesperidum destricta triumpho.

Cerberus extremi suprema est meta laboris.

Monosticha über die Mühen des Hercules

Als erste ist die Mühe des cleonäischen Löwen ertragen, als nächste erlegte er mit Feuer und Fackel die lernaeische Hydra. Bald durchbohrte die dritte Gewalt den erymanthischen Eber. Viertens trug er das goldene Geweih der leichtfüßigen Hindin davon. Die Stymphalischen Vögel vertrieb er in der fünften Gefahr. Sechstens beraubte er die thrakische Amazone ihres Gürtels. Der siebte Aufwand der Mühe war in den Ställen des Augias. Der achte Siegesruhm wird durch die Vertreibung des Stieres gezählt. In den Gespannen des Diomedes liegt der neunte Sieg. Durch den Tod des Geryon gibt Spanien die zehnte Siegespalme. Im elften Triumph sind die Äpfel der Hesperiden herunter gepflüickt. Cerberus ist das letzte Ziel der äußersten Mühe.

Sidonius wie Ausonius verfolgen auf unterschiedlichen Weisen und mit unterschiedlichen Mitteln letztlich doch vergleichbare Ziele, nämlich die Demonstration ihrer Fähigkeiten zu artistisch anspruchsvoller Darstellung. Beiden Autoren gemeinsam ist, dass sie dabei keine Berührungsangst auch vor Themen der paganen Mythologie und Götterwelt haben. ${ }^{54}$ Für Ausonius ist das in erster Linie ein Bildungsgut, das neben christlichem Bildungsgut als poetisches Material zur Verfügung steht. Das gilt auch prinzipiell für seinen jüngeren Landsmann Sidonius. Und dabei stehen dann

53 The Works of Ausonius, ed. with Introduction and Commentary by R. P. H. Green, Oxford 1991, z. St. 54 Vgl. Ulrich Schmitzer, Amor in der Unterwelt. Zum Gedicht Cupido Cruciatus des Ausonius. in: ders. (Hrsg.), Suus cuique mos. Beiträge zur paganen Kultur des lateinischen Westens im 4. Jahrhundert n.

Chr., Göttingen 2006 (Vertumnus 1), 167-184. 
die Ein-Wort und die Ein-Vers-Darstellungen letztlich auf einer Ebene: Sie nützen den tradierten paganen Stoff, um daran ihre formale Meisterschaft zu demonstrieren, unbeschadet der Tatsache, dass der Stoff geistesgeschichtlich eigentlich längst obsolet ist. Während Ausonius Christliches (wie in der Ephemeris) und Paganes ohne wesentlichen Unterschied für solche Demonstrationen verwendet, beschränkt sich Sidonius sogar völlig auf die paganen Mythen. Allenfalls subkutan kommt Christliches ins Spiel: So erscheint Sidonius' Hercules beinahe wie ein Gegenstück zu christlichen Märtyrern (ohne dass er allegorisierend in diese Reihe integriert würde) ${ }^{55}$ - die es allerdings in seiner Zeit auch schon nicht mehr gab. Damit wird ein wichtiger Teilaspekt der christlichen Gedankenwelt frei, um das Spiel mit dem Mythos zu unterstützen. Das konnte man selbstverständlich auch in Sidonius' Tagen nicht offen proklamieren, aber als literarische Strategie war es eine legitime Option geworden.

Im Rahmen von carm. 9 ist der Hercules-Abschnitt (anders als bei Ausonius und auch anders als im Epithalamium carm. 15) Teil eines kontinuierlich durchlaufenden Katalogs. In der Fortsetzung grenzt Sidonius seine Themenwahl weiter ab gegen die Mythen von Arethusa (101-105), Tantalus, Pelops und Thyest (106-116), Paris und den Beginn des Troianischen Krieges, den Ilias-Stoff also bis zur Eroberung Troias (117129), Odysseus und Achill (130 - 167) - all das wäre ja noch euhemeristisch heilbar oder sogar christlich allegorisierbar. ${ }^{56}$ Wirklich in den Kernbereich paganer Mythoreligion geht es dann in den folgenden Versen (carm. 9,168-180): ${ }^{57}$

\author{
Non divos specialibus faventes \\ agris, urbibus insulisque canto, \\ Saturnum Latio Iovemque Cretae \\ Iunonemque Samo Rhodoque Solem \\ Hennae Persephonem, Minervam Hymetto, \\ Vulcanum Liparae, Papho Dionem, \\ Argis Persea, Lampsaco Priapum, \\ Thebis Evhion Ilioque Vestam, \\ Thymbrae Delion, Arcadem Lycaeo, \\ Martem Thracibus ac Scythis Dianam,
}

$55 \mathrm{Zu}$ Herakles/Hercules im christlichen Denken siehe Abraham J. Malherbe, Herakles, RAC 14 (1988), 568-583. Wenn unser Eindruck nicht trügt, dann verfährt Sidonius komplementär zu den Kirchenvätern (sofern sie Hercules nicht als Inkarnation unchristlichen Verhaltens ablehnten, sondern ihn wegen seiner virtus in die eigene Gedankenwelt integrierten): Er macht Hercules nicht zum Teil der christlichen Welt, sondern transferiert die Märtyrer in die gedankliche Sphäre des Hercules. Siehe außerdem Marcel Simon, Hercule et le Christianisme, Paris 1955 (Publications de la Faculté des Lettres de l’Université de Strasbourg).

56 Siehe z. B. Ulrich Schmitzer, Odysseus - ein griechischer Held im kaiserzeitlichen Rom, in: Andreas Luther (Hrsg.), Odyssee-Rezeptionen, Frankfurt 2005, 33-53, hier: 49f. Siehe auch den Beitrag in diesem Band von Fabienne Jourdan, Orpheus and ,Orphism' in the Christian Literature (in Greek) of the First Five Centuries.

57 Stefania Santelia, Sidonio Apollinare e gli dèi pagani (a proposito di Carm. 9,168-180), Invigilata lucernis 21 (1999), 341-355 (mit zahlreichen Einzelerklärungen und vorausgehenden Parallelstellen, aber ohne weitergehende Interpretation). 
quos fecere deos dicata templa, tus, sal, far, mola, vel superfluarum consecratio caeremoniarum.

Nicht singe ich von Göttern, die besonderen Fluren, Städten, Inseln gewogen waren, wie Saturn Latium, Iuppiter Creta, Iuno Samos und Sol Rhodos, Persephone Henna, Minerva dem Hymettos, Vulcan Lipari, Venus Paphos, Perseus Argos, Priapus Lampsakos, Euhion Theben und Vesta Troia, Thymbra dem delischen Apollo, Arkadien dem Lykaios, Mars den Thrakern und Diana den Skythen, [von Göttern also,] welche die geweihten Tempel zu Göttern machten, nämlich Weihrauch, Salz, Getreide, Kuchen oder die Weihe überflüssiger Riten.

Auch hier muss man genau lesen: Die olympischen und nicht-olympischen Götter werden nicht prinzipiell angezweifelt. Ihre Existenz ist eine poetische Option, ihr Kult aber, durch den sie zur religiösen Realität würden, ist aber unter den Rahmenbedingungen des Christentums nicht mehr akzeptabel - und kaum einer wird in Sidonius' Zeit und Umwelt tatsächlich noch heidnische Opfer im vollen Umfang wie vor der Konstantinischen Wende vollzogen haben. Auch das macht die Scheidung zwischen Mythos und Kult für den Autor leichter.

Und kaum weniger herausfordernd sind die unmittelbar folgenden Hinweise auf die verschiedenen heidnischen Mysterien bis hin (durch eine unmittelbar vorausgehende lacuna im Kontext verunklärt) zum Vestakult (carm. 9,198-200):58

ex ipsis rapuit deos favillis,

per templum male fluctuante flamma

gaudens lumine perdito Metellus.

Und aus der Asche selbst riss die Götter - da durch den Tempel übel die Flamme wogte - froh Metellus, obwohl er sein Auge verlor.

Sidonius zeigt keine Berührungsangst, er qualifiziert die Götter und die zugehörigen Sagen nicht durch negative Attribute ab (siehe oben) ${ }^{59}$ - das hat er nicht nötig, sondern er kann sie als Stoffe sui iuris bestehen lassen, auch wenn er sie nicht bedichten möchte.

Die folgenden Passagen des carmen 9 sind für unsere Zwecke weniger wichtig, hierbei geht es dann nicht mehr um antike und pagane Stoffe, sondern um antike Dichter - ein umfangreicher Dichterkatalog, der viel auch über die Kanonisierung der

58 Die Geschehnisse um die Rettung des Palladium aus dem brennenden Vestatempel durch Caecilius Metellus, der trotz dieser heldenhaften Tat erblindete, da er dabei das für Männer eigentlich unzugängliche Heiligtum betreten hatte, sind mitsamt den antiken Quellen kurz zusammengefasst bei Barbara Kowalewski, Frauengestalten im Geschichtswerk des T. Livius, München/Leipzig 2002, 339. 59 Vgl. im Gegensatz dazu z. B. Ov. met. 5,319f. falsoque in honore Gigantas / ponit (eine Muse über den abzulehnenden Gesang der Pieriden). 
klassischen griechischen und lateinischen Literatur ${ }^{60}$ in der Spätantike lehrt und der nahtlos in zeitgenössische Literaturszene übergeht (carm. 9,302-310): ${ }^{61}$

Sed ne tu mihi comparare temptes, quos multo minor ipse plus adoro, Paulinum Ampeliumque Symmachumque, Messalam ingenii satis profundi, et nulli modo Martium secundum, dicendi arte nova parem vetustis Petrum et cum loquitur nimis stupendum, vel quem municipalibus poetis praeponit bene vilicum senatus.

Aber sollst nicht versuchen, die mit mir zu vergleichen, die ich - selbst viel jünger - viel mehr verehre, den Paulinus, Ampelius und Symmachus, Messala von genügend tiefschürfendem Geist und den Martius, der hinter keinem zurückstehen muss, Petrus, durch die neue Kunst der Rede gleich den Alten und, wenn er spricht, über die Maßen staunenswert, oder den Verwalter/Vilicus, den der Senat mit Recht den Dichtern aus den Provinzstädten vorzieht.

Die Einschätzung der poetischen Verhältnisse vollzieht sich in den durchaus geläufigen Bahnen antiken literaturgeschichtlichen Denkens. Die Autoren der Vergangenheit sind der Maßstab für die Bewertung der gegenwärtigen, ohne dass damit automatisch eine Abwertung verbunden wäre. ${ }^{62}$ Sidonius macht demgemäß auch keinen Unterschied zwischen traditionell-paganen und modern-christlichen Autoren. Sie erscheinen vielmehr in einer langen kontinuierlichen Reihe.

Sidonius lenkt nun am Ende seines langen Katalogs in wenig vorhersehbarer Weise das Gedicht in andere Bahnen. Dennoch bleibt die Frage noch unbeantwortet, was Sidonius denn nun anstelle der zurückgewiesenen Stoffe bedichten will. Wird er ein poetisches, gar christliches Gegenprogramm entwickeln? Wird er damit auch den angeredeten Felix auf eine entsprechende Höhe heben? Doch es kommt anders (carm. 9,318-328): $:^{63}$

60 Carm. 9,269-270 enthält einen der frühesten Hinweise auf Ovids Exil non qui tempore Caesaris secundi / aeterno incoluit Tomos reatu; vgl. auch carm. 23,158-161 et te carmina per libidinosa / notum, Naso tener, Tomosque missum, / quondam Caesareae nimis puellae / ficto nomine subditum Corinnae. $61 \mathrm{Zu}$ den Namen siehe die Erläuterungen von Anderson (s. Anm. 1) z. St. Es handelt sich durchgängig um zeitgenössische Dichter, wobei über Petrus nichts bekannt ist und bei (V)vilicus unklar bleiben muss, ob es sich um einen Eigennamen oder ein Amt handelt (siehe Anderson z. St.). Loyen (s. Anm. 1) bezieht vilicus als Umschreibung auf Flavius Merobaudes.

62 Die Formulierung erinnert an Ov. trist. 4,10,55f. utque ego maiores, sic me coluere minors / notaque non tarde facta Thalia mea est. Die mittlere Position in der Dichterhierarchie entspricht der mittleren Stellung in der altersmäßigen Abfolge.

63 Siehe auch Lobato (s. Anm. 39), 110-114. Anderson (s. Anm. 1), lv, Anm. 1 diskutiert die buchgeschichtlichen Implikationen von rarae ... brevique chartae, doch ist sehr die Frage, ob man auf dieser Realienebene dem Text wirklich beikommt oder ob nicht viel eher der literarkritische Aspekt, der Anschluss an die libellus-Thematik vom Anfang des Gedichts einschlägig ist. 


\begin{abstract}
Nos valde sterilis modos Camenae rarae credimus hos brevique chartae, quae scombros merito piperque portet. Nam quisnam deus hoc dabit reiectae, ut vel suscipiens bonos odores, nardum, ac pinguia Nicerotianis quae flagrant alabastra tincta sucis, Indo cinnamon ex rogo petitum, quo Phoenix iuvenescit occidendo, costum, malobathrum, rosas, amomum, myrrham, tus opobalsamumque servet?
\end{abstract}

Wir aber vertrauen diese Weisen unserer sehr unfruchtbaren Muse selten einer Papyrusrolle an, und dann nur einer kleinen, die besser Makrelen und Pfeffer enthalten sollte. Denn welcher Gott wird der Zurückgewiesenen (Rolle) geben, dass sie gar gute Düfte aufnimmt und Narde sowie die fetten Alabastergefäße, die getränkt mit den Essenzen des Niceros brennen, Zimt aus dem indischen Scheiterhaufen gewonnen, wo der Phoenix sich verjüngt, indem er stirbt, Kostwurz, Salböl, Rosen, Balsam, Myrrhe, Weihrauch, Balsam bringt?

Sidonius' Muse ist nach dieser eigenen Charakteristik sterilis, ${ }^{64}$ also wenig Ertrag bringend oder ganz unfruchtbar. Sie reicht nur für ein kurzes Schriftstück aus, dessen Träger als Einwickelpapier für Fische, Gewürze oder Kräuter bessere Verwendung fände, aber nicht für verfeinerte Genüsse (im Bild der duftenden Essenzen geschildert) taugt. Das ist eine schonungslose Selbstdiagnose: Sidonius hat nicht die Fähigkeit zu schöner Dichtung. Darüber hinaus führt sie zur generellen Feststellung, dass die traditionellen, von paganen Inhalten getragene Dichtung tot ist (einer der vielen immer wieder ausgerufenen und doch niemals eingetretenen Tode der Literatur) - so wie auch die paganen Orakel ihren Dienst einstellten (die bekannte Antwort der delphischen Sibylle an Julian; Artemii Passio 35,31-33 = Philostorgios 7,1c): E"ا $\pi \alpha \tau \varepsilon \tau \tilde{\varphi}$

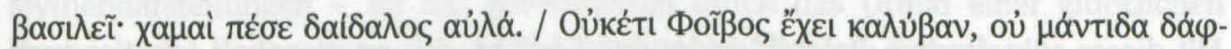

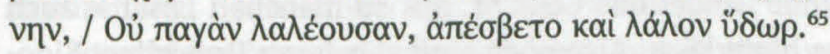

Doch die Form, in der diese anscheinend schonungslose Selbstdiagnose daher kommt, ist voller Ambivalenz und führt in ein interpretatorisches Dilemma: Sidonius hat ja in seiner Priamelreihe über gut dreihundert Verse sehr wohl gezeigt, dass er all die Mythen kennt und gewiss ein geeigneter Autor für ihre Umsetzung wäre, indem er sie paradoxerweise gerade nicht behandelt.

Gerade diese praeteritio zeigt in einer klassischen rhetorischen Volte, dass diese Mythen eben doch mögliche Stoffe der Literatur sind, dass es keine dichtungsexternen, weltanschaulichen Gründe gibt, sie nicht zu behandeln. Insofern bleibt es allein

64 Die Junktur scheint singulär: Egidio Forcellini, Totius latinitatis lexicon ( ${ }^{4} 1864-1926$, Vol. 4a, 483) bietet s.v. sterilis an vergleichbaren Wendungen lediglich Hinweise auf Plin. epist. 5,2 steriles epistulae; 5,17 sterile saeculum; Iuv. 7,203 sterilis cathedra; vgl. außerdem Sen. ben. 2,27,1 Lentulus ... ingenii fuit sterilis (nach OLD).

65 „Sagt dem Kaiser: Zu Boden fiel das kunstreiche Gebäude. Phoibos hat kein Obdach mehr, keinen weissagenden Lorbeer, keine sprechende Quelle, versiegt ist das mit Sprache begabte Wasser.“ 
eine Frage der jeweiligen poetischen Fähigkeiten. Indem Sidonius diese für sich verneint, setzt er die wohlbekannte recusatio-Technik ${ }^{66}$ fort, die unter dem Vorwand des mangelnden Talents große Themen ablehnt - conantem debilitabit onus (Ov. trist. 2,334) - und sie anderen, vorgeblich besser geeigneten zuweist. Das ist schon in der klassischen Dichtung ein kalkuliertes Verfahren, das in Wahrheit die ästhetische Überlegenheit der eigenen Dichtung unter Beweis stellen soll, doch mit der spezifischen Akzentuierung, dass zunächst überhaupt kein Gegenprogramm vorgelegt wird.

Bevor der Text - immerhin ein Einleitungsgedicht zu einem Gedichtbuch - ganz und gar in der Aporie endet, dreht sich noch einmal die Argumentationsrichtung. Denn obwohl andere, vor allem der Bruder des Felix, als Dichter zu Ehren des Felix eigentlich viel besser geeignet wären als Sidonius, will er doch das poetische Wagnis auf sich nehmen, wenn auch auf einem leichten, von Moral- und Kunstrichtern - die Catones stehen für beides ${ }^{67}$ - billig zu kritisierendem Terrain (carm. 9,338-346):
sed nec turgida contumeliosi
lectoris nimium verebor ora,
si tamquam gravior severiorque
nostrae Terpsichores iocum refutans,
rugato Cato tertius labello
narem rhinoceroticam ${ }^{68}$ minetur.
Non te terreat hic nimis peritus;
verum si cupias probare, tanta
nullus scit, mihi crede, quanta nescit.

Aber ich fürchte nicht die aufgeblasenen Mäuler der verächtlichen Leser, wenn jemand gleichsam Ernsthafterer und Strengerer unserer Terpsichores Scherz verschmäht und als dritter Cato mit kraus gezogener Lippe eine Rhinozerosnase droht. Auch dich soll dieser allzu Kundige nicht erschrecken. Wenn du die Wahrheit erfahren willst: So viel weiß keiner, glaube mir, wie er nicht weiß.

Mit dieser sokratischen Pointe ${ }^{69}$ endet das Gedicht, das so manchen Leser - auch modernen - durchaus ratlos hinterlässt. Also noch einmal gefragt: Bezeichnet Sidonius damit den Tod der Poesie ${ }^{70}$ Oder ist das eine Variante des aus der klassischen lateinischen Dichtung wohlbekannten Topos, wonach Kleindichtung vordergründig mit der Großdichtung nicht mithalten kann, der Autor aber aufgrund seines Unvermögens nichtsdestoweniger die weniger prestigeträchtige Kleindichtung betreibt und

66 Sieh dazu Wimmel (s. Anm. 43) passim.

67 Vgl. Loyen (s. Anm. 1), z. St. Siehe auch den (möglichen) Hinweis auf P. Valerius Cato als Kunstrichter im Gallus-Papyrus non ... Kato, iudice te vereor; dazu Mario Capasso, Il ritorno di Cornelio Gallo. Il papiro di Qasr Ibrîm venticinque anni dopo, Napoli 2003, 65-73.

68 Im grotesken Bild ist Hor. sat. 1,6,5 [non] naso suspendis adunco (über Maecenas) fortgeschrieben. 69 Zur Bedeutung der klassischen Philosophie (und der Philosophen) für Sidonius generell siehe auch Bernhard Hebert, Philosophenbildnisse bei Sidonius Apollinaris. Eine Ekphrasis zwischen Kunstbeschreibung und Philosophiekritik, Klio 70 (1988), 519-538.

70 So Lobato (s. Anm. 39). 
sich in Wahrheit überlegen zeigt ${ }^{71}$ - noch dazu in einer perfekten poetischen Architektur. $^{72}$

Ein Antwort ergibt sich nicht aus dem Einzelgedicht, sondern erst aus dem Blick auf die gesamte Sammlung der carmina minora, auf die insgesamt fünfzehn Gedichte:

\section{9: Widmungsgedicht an Felix - 346 Verse}

10: Praefatio zum ersten Epithalamium - 22 Verse

11: Epithalamium für Ruricius und Hiberia - 133 Verse

12: An den Senator Catullinus - 22 Verse

13: An Kaiser Maiorian - 40 Verse

14: An Polemius: Prosabrief mit angehängter Praefatio zum Epithalamium - 30 Verse

15: Epithalium für Polemius und Araneola - 201 Verse

16: Dankgedicht an den Bischof Faustus - 127 Verse

17: An den Senator Ommatius - 20 Verse

18: Über die Bäder seiner Villa - 12 Verse

19: Über sein Schwimmbecken - 4 Verse

20: An seinen Bruder Ecdicius - 4 Verse

21: Über einen des Nachts gefangenen Fisch - 4 Verse

22: Sidonius an seinen Freund Leontius (Prosa), der Burgus des Pontius Leontius - 235 Verse

23: An Cosentius - 512 Verse

24: Geleitgedicht an das Buch - 101 Verse

Aufgrund ihres Umfangs fallen die sehr kurzen Gedichte - insgesamt vier - für eine nähere Betrachtung aus. Von den verbleibenden elf sind neun, also die überwältigende Mehrzahl voll mit Inhalten aus der traditionellen paganen Götter- und Mythenwelt. So wird in carm. 15, dem bereits anzitierten einen der beiden Epithalamien der Tempel der athenischen Minerva zum Hof der Weisheit der sieben klassischen Philosophen - von Pythagoras bis Thales ${ }^{73}$ - und Webewerkstatt für textile Kunstwerke mit zahllosen Mythendarstellungen - all das gerechtfertigt durch das Urbild einer glücklichen Hochzeit, der Hochzeit von Thetis und Peleus (nicht der von Kanaa).

So wird der burgus des Pontius Leontinus in einer vor allem auf Statius zurückweisenden Tradition unter Anrufung der Musen ${ }^{74}$ als mythischer Herrschersitz verklärt und auf eine Begegnung von Dionysos und Apollo zurückgeführt (wobei sich Sidonius aus dem gesamten Arsenal von Attributen, Begleitern und Taten bedient, die ihm die Tradition zur Verfügung stellt). Daraus entsteht eine Ekphrasis, die den Vergleich mit Ovid und eben Statius nicht zu scheuen braucht. So kommen in carm. 11, dem ersten

71 Siehe z.B. Silvia Condorelli, Il poeta doctus nel V secolo D.C. Aspetti della poetica di Sidonio Apollinare, Napoli 2008.

72 Lobato (s. Anm. 39), 124.

73 Siehe zu Letzterem nunmehr Andreas Schwab, Thales von Milet in der frühen christlichen Literatur. Darstellungen seiner Figur und seiner Ideen in den griechischen und lateinischen Textzeugnissen christlicher Autoren der Kaiserzeit und Spätantike, Berlin/Boston 2011 (Studia Praesocratica 3), 312326.

74 Siehe zur Bedeutung der Musen für Sidonius generell Jean-Marie André, Le culte des Muses dans l'esthétique de Sidoine Apollinaire, Aevum 83 (2009), 209-220. 
Hochzeitsgedicht, die Schwäne der Venus aus ihrem übernatürlichen Tempel, um das Hochzeitspaar zu ehren.

Und selbst wenn einmal christliche Inhalte im Vordergrund stehen, wie in carm. 16 mit guten Grund, ist es doch an den Bischof Faustus gerichtet, dann geschieht das in eigenartiger Akzentuierung (carm. 16,1-10):
Phoebum et ter ternas decima cum Pallade Musas
Orpheaque et laticem simulatum fontis equini
Ogygiamque chelyn, quae saxa sequacia flectens
cantibus auritos erexit carmine muros, sperne, fidis; magis ille veni nunc spiritus, oro, pontificem dicture tuum, qui pectora priscae intrasti Mariae, rapiens cum tympana siccus Israel appensi per concava gurgitis iret aggeribus vallatus aquae mediasque per undas pulverulenta tuum clamaret turba triumphum;

Den Phoebus und die dreimal drei Musen zusammen mit Pallas, der zehnten, und Orpheus und das vorgetäuschte Wasser der Pferdequelle und die ogygische Leier, die die ihr folgenden Felsen im Gesang erweichte und durch das Lied die ihr lauschenden Mauern errichtete, die verschmähe, meine Saite; vielmehr komm nun jener Geist, so bitte ich, der deinen Bischof künden wird, der du das Herz der älteren Maria $^{75}$ betreten hast, als Israel, die Tamburins fortreißend, trockenen Fußes durch die Krümmung der Fluten ging, von den Dämmen des Wassers schützend umgeben und als mitten durch die Wogen des Wassers die trockene Schar deinen Sieg laut verkündete.

Das ist beinahe in nuce das Verfahren des gesamten Gedichtbuches (allerdings mit dem Unterschied, dass hier der recusatio die positive Zielbestimmung folgt - eine Konzession möglicherweise an das geistliche Amt des Adressaten): Die heidnischen Mythen und Götter sind auf diese Weise präsent, gerade weil sie als absent charakterisiert sind. Sie hinterlassen jenseits aller persönlicher Religiosität eine poetische Leerstelle, die nur mit Mühe durch die Stoffe und das Personal der Bibel gefüllt ${ }^{76}$ werden kann. Diese schmerzliche Lücke, so sollte durch die bisherige Interpretation plausibel geworden sein, ist für Sidonius in seinem literarischen Werk aber nicht tolerabel. Und so füllt er sie entweder durch die direkte Erwähnung oder noch kunstvoller, indem er sie so beredt nicht erwähnt, dass sie eben doch zum Gegenstand der Dichtung werden.

Auch wenn die Gedichte der carmina minora wohl entstanden und publiziert sind, bevor Sidonius ins Bischofsamt berufen wurde, ${ }^{77}$ ist es doch bemerkenswert, in wel-

75 Exodus 15,20f. (Luther-Übersetzung): „Und Mirjam, die Prophetin, Aarons Schwester, nahm eine Pauke in ihre Hand, und alle Weiber folgten ihr nach hinaus mit Pauken im Reigen. Und Mirjam sang ihnen vor: Laßt uns dem HERRN singen, denn er hat eine herrliche Tat getan; Roß und Mann hat er ins Meer gestürzt."

76 Zum biblisch-theologischen Hintergrund des gesamten Gedichts und damit zur Theologie des Sidonius insgesamt siehe Harries (s. Anm. 8), $108 \mathrm{f}$.

77 Siehe Schetter (s. Anm. 34). 
chem Umfang die Mythen ${ }^{78}$ gegen die ein Tertullian, Arnobius oder Lactanz so leidenschaftlich gekämpft hatten,${ }^{79}$ nun wieder ihren Platz beanspruchen können. ${ }^{80}$ Die Nachwehen der scharfen apologetischen Auseinandersetzungen, die bis tief ins 4. Jahrhundert zu spüren gewesen waren, hatten nicht nur ihr Brisanz, sondern auch ihre Funktion verloren. Die Christen, die noch von Julian Apostata als intellektuell nicht in der Lage, an dieser Vermittlung teilzuhaben, abgewertet worden waren, sehen sich nun allein im Stande, auch die pagane Tradition zu bewahren. Die heidnischen Götter und deren Sagenwelt werden wie schon für Ausonius so jetzt auch für Sidonius Gegenstand der Kultur, nicht der Religion und Moral. Sie sind Teil der imaginären Bibliothek (und auch der realen Bibliotheken, aus denen sie eben nicht eliminiert werden), ${ }^{81}$ des umfassenden Wissensspeichers, ${ }^{82}$ dessen sich Sidonius bedient wie er ihn auch selbst bedient. Der Mythos wird, von Spezialfällen wie bei der Begegnung mit Bischof Faustus abgesehen, eben nicht in Kategorien des Glaubens und der religiösen Überzeugung gemessen, sondern ist Teil des kulturellen Gemeinguts, das in der christlichen Umwelt eine neue Heimat gefunden hat. ${ }^{83}$

Nicht nur die Mächtigen konnten sich im Glanz der Tradition sonnen, wenn sie in den panegyrischen Texten, wie im carmen 7, wie einst Alexander der Große und andere bedeutende Männer in mythologischem Ambiente gepriesen wurden. Die Bildung als Argument für die Eignung zum Kaiser müssen sogar die barbarischen Westgoten und deren König Theoderich II. anerkennen, zumal Theoderich wohl sogar einmal Schüler

$78 \mathrm{Zu}$ ähnlichen Beobachtungen über die Rolle der Religion und Mythologie in den Briefen des Sidonius siehe David Amherdt, Sidoine Apollinaire. Le quatrième livre de la correspondance. Introduction et commentaire, Bern et al. 2001 (Sapheneia 6), $37 \mathrm{f}$.

79 Zur ebenfalls dezidiert ablehnenden Haltung des Paulinus von Nola siehe Robert Kirstein, Paulinus Nolanus. Carmen 17, Basel 2000 (Chrêsis 8).

80 Zur ambivalenten Haltung der Christen gegenüber der traditionellen Bildung insgesamt siehe Alexander Demandt, Die Spätantike. Römische Geschichte von Diocletian bis Justinian 284-565 n.Chr., 2. überarbeitete Auflage, München 2007 (HdAW 3,6), 490-492.

81 Siehe auch Natalia Rusnac, From villa to Cloister. The Religious Transformation of the Book in Late Antique Gaul, Viator 44 (2013), 1-24.

82 Zur Idee der Bibliothek und des Lesens siehe anhand von Sidon. epist. 4,11,6 (triplex bibliotheca quo magistro Romana, Attica, Christiana fulsit: die Bibliothek des Claudius Mamertus; dazu Franz Bömer, Der lateinische Neuplatonismus und Neupythagoreismus und Claudianus Mamertus in Sprache und Philosophie, Leipzig 1936) Ulrich Eigler, Lectiones Vetustatis. Römische Literatur und Geschichte in der lateinischen Literatur der Spätantike, München 2003 (Zetemata 115), bes. 103-112. Siehe außerdem Ulrike Egelhaaf-Gaiser, Bleibende Klänge. Das hymnische Briefsiegel des Bischofs Sidonius (epist. 9,16), Millennium 7 (2010), 257-292 (v. a. mit Blick auf die Bedeutung des Horaz für die epistolographische Selbstdarstellung des Sidonius); Sigrid Mratschek, Identitätsstiftung aus der Vergangenheit. Zum Diskurs über die trajanische Bildungskultur im Kreis des Sidonius Apollinaris, in: Therese Fuhrer (Hrsg.), Die christlich-philosophischen Diskurse der Spätantike: Texte, Personen, Institutionen, Stuttgart 2008, 363-380 (zur Bedeutung von Plinius minor und Tacitus).

83 Siehe auch das Lob der traditionellen Bildung in christlichem Umfeld in Sidon. epist.4,1.Vgl. bündig Demandt (s. Anm. 80), 384f. über Sidonius’ Kritik an den Goten: „Das, was ihnen zur Humanität fehle, sei nicht die Bibel, sondern die Philosophie und Dichtung.“ 
des Avitus war und von diesem just die klassische Bildung gelernt hat. Das kehrt als Verdienst und Herrschertugend jetzt wieder zu Avitus zurück (carm. 7, 494-497): ${ }^{84}$

\author{
solumque moratur \\ quod cupias, nescisse Getas. mihi Romula dudum \\ per te iura placent, parvumque ediscere iussit \\ ad tua verba pater docili quo prisca Maronis \\ carmine molliret Scythicos mihi pagina mores.
}

Allein hindert mich noch, dass die Goten das nicht kennen, was du willst. Mir gefallen seit langem die Gesetze des Romulus durch dich, mein Vater befahl auf dein Wort hin, dass ich schon als kleines Kind genau lernte, womit mir Gelehrigem die alte Schrift durch die Dichtung des Vergilius Maro die skythischen Sitten weniger hart machte.

Das billigen auch die Götter in ihrer von Jupiter einberufenen Ratsversammlung, die als Rahmen den Anfang wie den Schluss des Panegyricus auf Avitus bildet. Vielmehr aber reicht die Wirksamkeit der paganen Mythen auch bis in die sich als personale Poesie gebende Kleindichtung und damit in die private Sphäre (bzw. deren literarische Konstruktion). Damit wird die Tradition der durch Kallimachos und seine Nachfolger in Rom begründeten gelehrten und anspielungsreichen Dichtung auch über die konstantinische Wende und deren Folgen fortgesetzt, nicht ganz bruchlos zwar, denn es kommen ja nun auch christliche Inhalte hinzu, aber im römischen Gallien eben auch ohne Autodafé.

Misst man Sidonius nicht mit dem sachfremden Maßstab des scheinbar Originellen und Authentischen, sondern an seinem Anspruch, das als vorbildlich und wichtig erkannte Wissen früherer Zeiten zu bewahren und für eine fundierte Bildung fruchtbar zu machen, dann ist auch Sidonius' Muse eben nicht sterilis. Vielmehr bringt sie Ertrag in einer Zeit, in der - zumindest für Sidonius in seiner gallischen Umwelt des 5. Jahrhunderts - die klassische Bildung mitsamt dem Mythos auch ideologiebefreit gelesen werden konnte und damit einen neuen, auf die künftigen Renaissancen vorausweisenden Wert bekam. ${ }^{85}$

84 Zum Goten- und Theoderichbild des Sidonius siehe Kaufmann (s. Anm. 18), 106-139.

85 Kaufmann (s. Anm. 18), 221-224 u. ö. weist mit Recht darauf hin, dass der Kreis der Gebildeten in dieser Zeit sehr klein war, doch ändert das nichts an der prinzipiellen Ausrichtung von Sidonius' Werk auf eben jene Adressaten. 